\title{
SISTEM ANALISIS BUTIR SOAL PADA CBT DENGAN METODE TEORI RESPON BUTIR
}

\author{
Wahyuni ${ }^{1}$, Muhammad Fahmi \\ Dosen STMIK Widya Cipta Dharma ${ }^{1,2}$ \\ Jalan M. Yamin No. 25 Samarinda 75123 \\ Sur-el : wahyuni@wicida.ac.id ${ }^{1}$, mfahmi@wicida.ac.id ${ }^{2}$
}

\begin{abstract}
Analysis of the quality of the items is carried out so that the questions made actually consist of quality items in order to measure learning outcomes. Currently, there are still many teachers who have not analyzed the questions they made because they think that analyzing the questions takes a long time and takes a lot of energy. As a result, many items used cannot produce correct data about student learning outcomes. Therefore, a Question Item Analysis System was made using the Website-based Item Response Theory method to determine the quality of the items presented. In this study, a website-based item analysis system was developed using the item response theory method with a 3PL approach model. This system is made one package with CBT. Responses from participants to analyze the items are obtained automatically when participants take the CBT test.
\end{abstract}

Keywords: Item Analysis System, Item Response Theory, Computerized Based Test

\begin{abstract}
Abstrak : Analisis kualitas butir soal dilakukan agar soal yang dibuat benar-benar terdiri dari butir soal yang berkualitas guna mengukur hasil belajar. Saat ini masih banyak tenaga pengajar yang belum melakukan analisis soal yang mereka buat karena mereka beranggapan untuk melakukan analisis soal memerlukan waktu lama dan menguras banyak tenaga. Akibatnya banyak butir soal yang digunakan tidak dapat menghasilkan data yang benar tentang hasil belajar peserta didik. Oleh karena itu dibuatlah Sistem Analisis Butir Soal dengan metode Teori Respon Butir berbasis website untuk mengetahui kualitas dari butir-butir soal yang disajikan. Pada penelitian ini dibuat suatu sistem analisis butir soal berbasis website menggunakan metode teori respon butir dengan model pendekatan 3PL. Sistem ini dibuat satu paket dengan CBT. Respon jawaban dari peserta untuk menganalisis butir soal didapatkan secara otomatis ketika peserta mengikuti tes CBT.
\end{abstract}

Kata kunci: Sistem Analisis Butir Soal, Teori Respon Butir, Computerized Based Test

\section{PENDAHULUAN}

Computerized Based Test (CBT) adalah tes hasil belajar yang dilakukan dengan memanfaatkan komputer [1]. Pada pemakaian CBT tes disajikan tidak lagi menggunakan lembaran kertas, namun dikemas dalam sebuah aplikasi komputer. Hal ini menjadikan proses belajar akan lebih praktis untuk dikemas dan dilaksanakan. Bahkan ujian nasional pun kini menggunakan CBT atau bisa juga dikenal dengan UNBK (Ujian Nasional Berbasis
Komputer) [2]. Kemendikbud melalui Badan Standar Nasional Pendidikan (BSNP) mengeluarkan peraturan BSNP Nomor: 0034/BNSP/XII/2015 tentang prosedur operasional standar penyelenggaraan ujian nasional tahun pelajaran 2015/2016 [3]. Pada tahun 2015 UN dilaksanakan dalam dua bentuk yaitu tertulis (paper and pencil test -PBT) dan berbasis komputer (computer based test-CBT) dengan bentuk soal pilihan ganda .

Terlebih lagi pada masa pandemic Covid19 yang sekarang tengah melanda Indonesia. 
CBT dirasa wajib digunakan di dalam dunia pendidikan, mulai dari Sekolah Dasar (SD) hingga ke Perguruan Tinggi. Namun bank soal pada CBT harus menyediakan soal yang berkualitas.

Analisis kualitas butir soal dilakukan agar soal yang dibuat benar-benar terdiri dari butir soal yang berkualitas guna mengukur hasil belajar [4]. Dengan menganalisis soal, guru dapat memperoleh hasil informasi yang dapat digunakan untuk mengambil keputusan dalam program yang telah dibuat. Menganalisis soal sangat penting dilakukan, untuk memperbaiki soal yang buruk, agar soal yang diujikan pada waktu berikutnya lebih baik.

Saat ini masih banyak tenaga pengajar yang belum melakukan analisis soal yang mereka buat karena mereka beranggapan untuk melakukan analisis soal memerlukan waktu lama dan menguras banyak tenaga [4]. Akibatnya banyak butir soal yang digunakan dalam tes tidak dapat menghasilkan data yang benar tentang hasil belajar peserta didik. Apabila keputusan yang diambil berdasarkan data yang tidak akurat, maka keputusan tersebut tidak dapat dipertanggung jawabkan.

Oleh karena itu dibuatlah Sistem Analisis Butir Soal dengan metode Teori Respon Butir berbasis website untuk mengetahui kualitas dari butir-butir soal yang disajikan. Sehingga diharapkan dengan menyajikan butir soal yang berkualitas pada peserta tes, maka hasil akhir yang didapatkan bisa tepat dan dapat dipertanggung jawabkan. Studi kasus akan dilakukan pada soal tes penerimaan mahasiswa baru STMIK Widya Cipta Dharma.
Sedangkan untuk STMIK Widya Cipta Dharma sendiri sebagai tempat penelitian, dapat menggunakan sistem ini dalam jangka panjang dan untuk berbagai kebutuhan. Dapat digunakan dalam bank soal Penerimaan Mahasiswa Baru, dan bisa digunakan oleh para dosen untuk menganalisis soal Ujian Tengah Semester (UTS) dan Ujian Akhir Semester (UAS) bagi mahasiswa.

Penelitian tentang sistem analisis butir soal dengan metode yang sama telah banyak dilakukan antara lain :

1. Evaluasi Pembelajaran Menggunakan Item Response Theory Model 2PL [5].

2. Pengembangan Sistem Informasi Analisis Butir Soal Terintegrasi Dengan CBT Menggunakan Teori Classical Measurements [6].

3. Pengembangan Web Interface Untuk Analisis Item Response Theory Dengan Pendekatan Model Campuran dan Penerapannya Pada Bank Soal MGMP [7].

Pada penelitian Andriawan mengimplementasikan metode Teori Respon Butir dalam menganalisis butir soal. Metode tersebut digabungkan dengan sistem BEESMART. BEESMART merupakan sistem CBT seperti sistem UNBK yang digunakan untuk melatih para siswa sebelum menghadapi UNBK. Sistem BEESMART ini sendiri dibangun berbasis web. Model pendekatan Teori Respon Butir yang digunakan adalah model 2PL (Parameter Logistik). Hasil yang didapat adalah algoritma teori respon butir dapat digabungkan dengan sistem BEESMART dan dapat memberikan informasi hasil analisis butir soal. 
Pada penelitian Sholihul [6], dibuatlah suatu sistem informasi yang digunakan untuk menganalisis butir soal. Sistem informasi yang dibangun berbasis web. Sedangkan metode yang digunakan dalam menganalisis butir soal tersebut adalah metode klasik. Hasil yang didapatkan adalah sistem informasi tersebut dapat memberikan hasil analisis terhadap butir soal yang telah dianalisis menggunakan metode klasik.

Pada penelitian Utama [7], dibangunlah sebuah web interface untuk menganalisis dan menampilkan hasil dari analisis butir soal. Web interface yang dibangun menggunakan R-Shiny dan perhitungan analisis butir soal menggunakan $\mathrm{R}$ programming. Web interface ini hanya menghitung dan menganalisis butir soal yang selanjutnya akan ditampilkan. Untuk respon terhadap butir soal dari para peserta masih dilakukan secara manual. Hasil dari penelitian ini adalah web interface tersebut dapat memberikan informasi mengenail hasil analisis terhadap setiap butir soal.

Dari ketiga penelitian tersebut, maka dapat disimpulkan bahwa semuanya membangun sistem analisis butir soal berbasis web dan telah berhasil memberikan informasi mengenai butir soal yang telah dianalisis. Namun masih ada kekurangan dari masing-masing penelitian tersebut. Pada penelitian Andriawan [5], model pendekatan yang digunakan masih menggunakan model 2PL. Pada penelitian Sholihul [6], metode analisis butir soal yang digunakan masih menggunakan metode klasik. Sedangkan pada penelitian Utama [7], respon yang didapatkan untuk menganalisis butir soal masih dilakukan secara manual. Pada penelitian ini, peneliti mencoba untuk melengkapi kekurangankekurangan yang ada pada penelitian sebelumnya.

Pada penelitian ini akan dibuat suatu sistem analisis butir soal berbasis website menggunakan metode teori respon butir dengan model pendekatan 3PL. Sistem ini juga akan dibuat satu paket dengan CBT. Dengan dibuat satu paket dengan CBT, maka respon jawaban dari peserta untuk menganalisis butir soal didapatkan secara otomatis ketika peserta mengikuti tes CBT. Sehingga setiap saat soal dapat selalu dianalisis dan akan didapatkan hasil analisis yang baru. Dengan kata lain setiap soal akan memiliki hasil analisis yang up to date.

\section{METODOLOGI PENELITIAN}

\subsection{Computerized Based Testing}

Computer Based Testing merupakan ujian yang dikerjakan di komputer sehingga tidak memerlukan kertas, pena maupun pensil untuk menjawab pertanyaannya [8]. Soal nya tertulis di komputer dan lembar jawabannya juga disediakan di komputer sehingga kita hanya tinggal mengklik jawaban yang benar maupun salah atau tinggal mengetik kalau menjawab pertanyaan esay.

Computer Based Testing ini banyak diimplementasikan diberbagai bidang seperti bidang pendidikan maupun di dunia kerja. Di bidang pendidikan biasanya dipakai untuk menentukan berapa nilai tertinggi seorang siswa atau mahasiswa dalam menguasai satu mata pelajaran atau mata kuliah. Sedangkan di dunia 
kerja, Computer Based Testing digunakan untuk mengetahui kemampuan dasar dari seorang pelamar pekerjaan sehingga mempermudah bagian HRD dalam menyeleksi calon karyawan.

\subsection{Analisis Butir Soal}

Analisis tes dan butir soal merupakan suatu tahap yang harus ditempuh untuk mengetahui derajat kualitas suatu tes, baik tes secara keseluruhan maupun butir soal yang menjadi bagian dari tes tersebut [9]. Analisis tes dan butir soal bertujuan:

1. Mengetahui apakah tes atau soal yang digunakan untuk mengevaluasi sudah mampu mengukur apa yang sebenarnya ingin diukur melalui tes atau soal tersebut.

2. Mengetahui sejauh mana data atau informasi yang dihasilkan oleh tes maupun butir soal dapat diandalkan.

3. Mengetahui sejauh mana data yang dihasilkan oleh tes atau soal dapat berguna bagi proses pembelajaran.

\subsection{Teori Respon Butir}

Teori respon butir atau Item Response Theory (IRT) menggambarkan peluang menjawab butir soal secara benar berdasarkan tingkat kemampuan peserta tes dan butir soal yang diberikan [10]. Dalam pendekatan IRT kemampuan individu atau proficiency (disimbolkan dengan $\theta$ ) dan tingkat kesukaran butir atau difficulty (disimbolkan dengan b) berada pada satu dimensi yang sama.

Ada tiga model logistik dalam teori respons butir, yaitu model logistik satu parameter (1PL), model logistik dua parameter
(2PL) dan model logisitik tiga parameter (3PL). Perbedaan dari tiga model ini terletak pada banyaknya parameter yang digunakan dalam menggambarkan karakteristik butir soal dalam model yang digunakan. Parameter-parameter yang digunakan tersebut adalah indeks kesukaran, indeks daya beda butir dan indeks tebakan semu (pseudoguessing). Berikut penjelasan mengenai parameter-parameter tersebut [11]:

1. Indeks kesukaran, merupakan peluang untuk menjawab benar suatu soal pada tingkat kemampuan tertentu yang biasanya dinyatakan dalam bentuk indeks. Indeks tingkat kesukaran ini pada umumnya dinyatakan dalam bentuk proporsi yang besarnya berkisar $0,00-1,00$. Semakin besar indeks tingkat kesukaran yang diperoleh dari hasil perhitungan, maka semakin mudahlah soal tersebut. Dalam memperoleh nilai indeks ini adalah dengan melakukan perhitungan pada setiap butir soal dengan persamaan sebagai berikut [5]:

$$
\mathrm{b}=\frac{B A+B B}{L}
$$

Keterangan:

b : Indeks tingkat kesukaran yang dicari

BA : Jumlah jawaban benar siswa yang termasuk kelompok atas yang menjawab benar untuk tiap soal.

BB : Jumlah jawaban benar siswa yang termasuk kelompok bawah yang menjawab benar untuk tiap soal.

L : Jumlah siswa dari kelompok pandai dan kelompok kurang.

Penentuan kelompok atas dan bawah diambil $27 \%$ dari responden yang telah diurutkan skornya 
dari skor tertinggi ke skor terendah [12]. Klasifikasi indeks kesukaran adalah sebagai berikut:

1) Jika $0,00 \leq b \leq 0,30$ maka soal tergolong sulit.

2) Jika $0,31 \leq b \leq 0,70$ maka soal tergolong sedang.

3) Jika $0,71 \leq b \leq 1,00$ maka soal tergolong mudah.

2. Daya beda, merupakan kemampuan suatu butir soal yang dapat membedakan antara siswa yang telah menguasai materi yang ditanyakan dan siswa yang belum menguasai materi yang ditanyakan. Pada umumnya nilai indeks yang terdapat untuk daya pembeda berkisar antara 0 2. Semakin tinggi nilai daya pembeda soal maka semakin baik soal tersebut. Untuk memperoleh nilai daya pembeda soal dapat diperoleh dengan fungsi sebagai berikut [5]:

$a=\frac{2(B A-B B)}{N}$

\section{Keterangan:}

$\alpha$ : Daya beda soal.

BA : Jumlah jawaban benar kelompok atas.

BB : Jumlah jawaban benar kelompok bawah.

$\mathrm{N}$ : Jumlah siswa yang mengerjakan tes.

Klasifikasi daya beda adalah sebagai berikut [12]:

1) Jika $0,70 \leq a \leq 1,00$, maka soal baik sekali.

2) Jika $0,40 \leq a \leq 0,69$, maka soal baik.

3) Jika 0,20 $\leq a \leq 0,39$, maka soal cukup.

4) Jika $0,00 \leq a \leq 0,19$, maka soal jelek.

5) Jika a $<0,00$, maka soal jelek sekali.

3. Tebakan semu, ada kalanya butir soal berbentuk pilihan ganda sehingga responden yang tidak memiliki kemampuan pun masih mungkin menjawab benar melalui terkaan. Dalam bentuk probabilitas, katakana saja bahwa tingkat kebetulan pada jawaban benar adalah c, maka untuk butir ini, probabilitas jawaban benar karena kebetulan adalah $\mathrm{P} \odot=$ c. Adapun untuk menghitung tebakan semu dapat dilakukan persamaan sebagai berikut:

$\mathrm{c}=\frac{o}{o+K} *\left(\frac{100}{J P}\right)$

\section{Keterangan:}

c : tebakan semu soal.

$\mathrm{O}$ : jumlah respon peserta yang paling banyak yang memilih pilihan selain pilihan yang benar.

$\mathrm{K}$ : jumlah respon peserta yang memilih pilihan yang benar.

JP : jumlah pilihan yang ada pada soal.

Nilai tebakan semu berkisar antara 0 - 1 [13]. Suatu butir soal dikatakan baik jika nilainya tidak melebihi 1/JP.

\subsection{Tahapan Penelitian}

Penelitian ini dilaksanakan melalui beberapa tahapan pengembangan System Development Life Cycle (SDLV) sebagai berikut [14]:

1. Analisis, sistem yang ada di evaluasi. Kekurangan diidentifikasi. Ini dapat dilakukan dengan mewawancarai pengguna sistem dan berkonsultasi dengan personel pendukung.

2. Rencana dan Persyaratan, persyaratan sistembaru didefinisikan. Secara khusus, kekurangan dalam sistem yang ada harusditangani dengan proposal spesifik untuk perbaikan. Faktor-faktor lain yang didefinisikan 
termasuk fitur yang dibutuhkan, fungsi dan kemampuan.

3. Desain, sistem yang diusulkan dirancang. Rencana disusun mengenai konstruksi fisik, perangkat keras, sistem operasi, pemrograman, komunikasi dan masalah keamanan.

4. Pengembangan, sistem baru dikembangkan. Komponen dan program baru harus diperoleh dan diinstal. Pengguna sistem harus dilatih dalam penggunaannya.

5. Pengujian, semua aspek kinerja harus diuji. Jika perlu, penyesuaian harus dilakukan pada tahap ini.

\section{HASIL DAN PEMBAHASAN}

Adapun alur sistem yang akan di bangun adalah sebagai berikut:

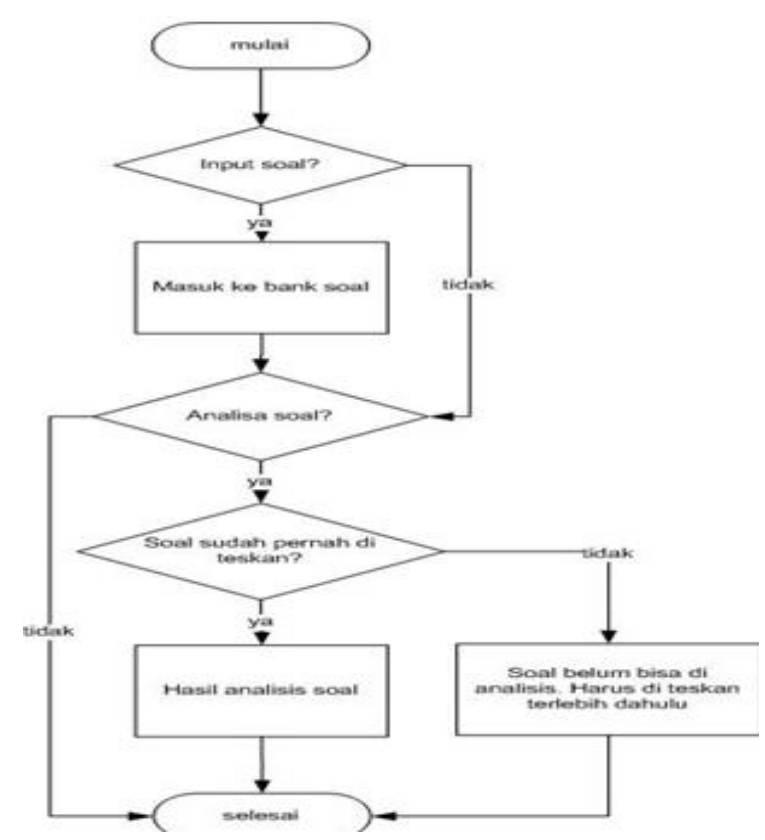

Gambar 1. Flowchart Alur Sistem

Pada gambar di atas dijelaskan bahwa pertama soal akan di inputkan ke dalam bank soal.
Jika soal sudah diinputkan, maka kita bisa masuk pada proses analisis soal. Namun soal yang bisa dianalisis adalah soal yang sebelumnya sudah pernah dijawab atau direspon oleh peserta tes. Jika soal sudah pernah direspon oleh peserta maka soal siap untuk dianalisis dan sistem akan menampilkan hasil analisis dari soal tersebut.

Rancangan sistem yang akan dibangun adalah sebagai berikut:

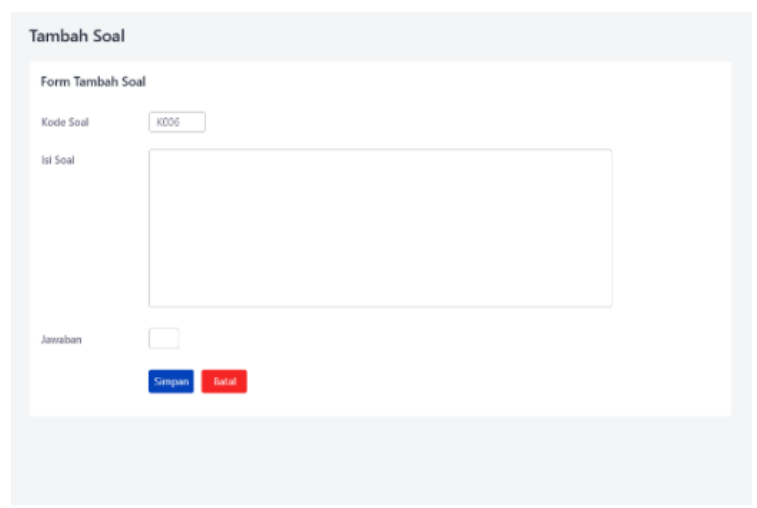

Gambar 2. Halaman Input Soal

Gambar 2 di atas merupakan rancangan halaman input soal yang akan masuk ke dalam bank soal.

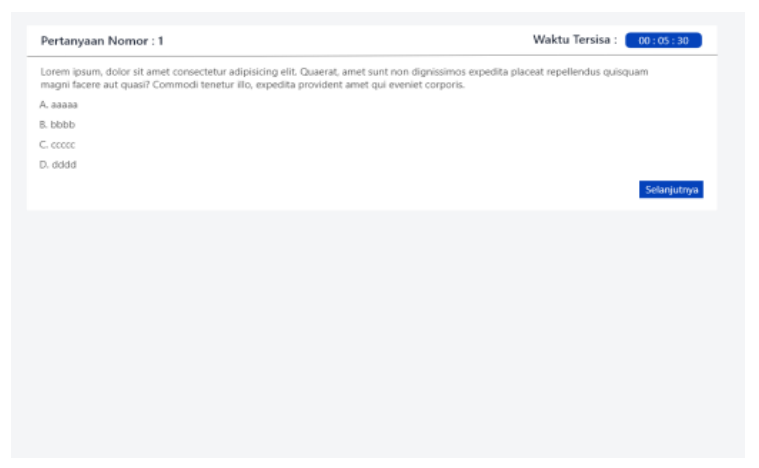

Gambar 3. Halaman Tes

Sedangkan gambar 3 merupakan halaman tes online atau CBT. Melalui halaman ini, maka sistem akan mendapatkan respon dari peserta untuk setiap butir soal yang diberikan. Setelah butir soal mendapatkan respon dari peserta, maka butir soal tersebut dapat dianalisis. 


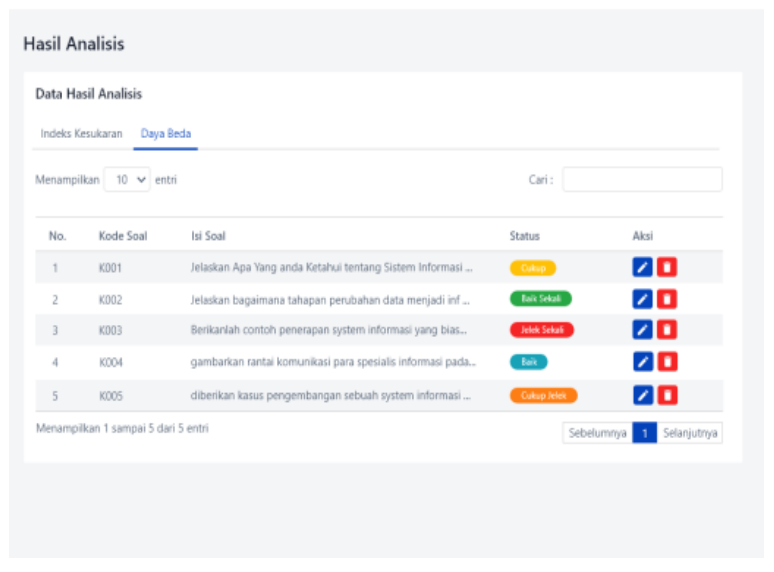

Gambar 4. Halaman Analisis Soal

Gambar 4 merupakan halaman analisis soal. Dimana pada halaman ini, diberikan informasi mengenai butir soal yang sudah dinalisis. Halaman analisis ini nantinya akan dibagi untuk setiap parameternya.

\section{KESIMPULAN}

Setelah dilakukan pengolahan sistem analisis butir soal ini, dapat disimpukan bahwa sistem ini sudah berjalan sebagaimana mestinya. Sistem ini dapat digunakan untuk menganalisis butir soal sehingga dapat dihasilkan butir soal yang berkualitas. Dengan memberikan soal yang berkualitas tentu saja hasil penilaian terhadap peserta ujian menjadi lebih tepat. Dan diharapkan sistem ini dapat digunakan untuk menganalisis butir soal dalam tes apa pun yang sifatnya pilihan ganda. Karena sistem ini dibuat fleksibel yang artinya siapapun bisa menggunakan sistem ini.

Karena sistem ini masih diterapkan pada sistem CBT, maka diharapkan untuk kedepannya sisem ini dapat diterapkan bahkan digabungkan di dalam sistem CAT. Karena sistem CAT saat ini sudah mulai banyak digunakan. Dimana dengan sistem CAT sistem dapat memberikan soal sesuai dengan kemampuan peserta yang tentunya berbeda-beda.

\section{DAFTAR PUSTAKA}

[1] Fitri Maiziani, "Efektivitas Computerized Based Testing Sebagai Sarana Tes Hasil Belajar," Kiprah, vol. 4, no. 1, pp. 15-32, Juni 2016.

[2] Pusat Penilaian Pendidikan. (2019) UNBK Pusat Penilaian Pendidik Kementrian Pendidikan dan Kebudayaan. [Online]. unbk.kemdikbud.go.id

[3] Baiq Desi Dwi Arianti, Yosi Nur Kholisho, Kholid Ismatulloh, and dkk., "Pelatihan Computer Based Test (CBT) Ujian Nasional Untuk Siswa SMK di Lombok Timur," Absyara: Jurnal Pengabdian Pada Masyarakat Bidang Pendidikan, Sains dan Teknologi, vol. 1, no. 1, pp. 22-32, Juli 2020.

[4] Risca Ferry Fergyana, "Analisis Kualitas Butir Soal Ujian Akhir Semester Ganjil Teori Kejuruan Kelas X Akuntansi SMK Muhammadiyah Wonosari Tahun 2016/2017," Program Studi Pendidikan Akuntansi Jurusan Pendidikan Akuntansi Fakultas Ekonomi Universitas Negeri Yogyakarta, Yogyakarta, Skripsi 2017.

[5] B Andriawan, "Evaluasi Pembelajaran Menggunakan Item Response Theory Model 2 Parameter Logistik," Universitas Islam Negeri Maulana Malik Ibrahim, Malang, Tesis 2019.

[6] Ahmad Sholihul, "PENGEMBANGAN SISTEM INFORMASI ANALISIS BUTIR SOAL TERINTEGRASI DENGAN COMPUTER BASE TEST ( CBT ) BERBASIS WEB MENGUNAKAN TEORI CLASSICAL MEASUREMENTS," Universitas Islam Nahdlatul Ulama , Jepara, Tesis oai:eprints.unisnu.ac.id:1544, 2018.

[7] Tika Clarinta Putri Utama, "Pengembangan Web Interface Untukanalisis Item Response Theory Dengan Pendekatan Model 
Campuran Dan Penerapannya Pada Bank Soal Mgmp," Universitas Jember, Jember, Tesis http://repository.unej.ac.id//handle/1234567 89/93839, 2015.

[8] Alhamidi, "Mengukur Kemampuan Bahasa Inggris Siswa Sekolah Menengah Atas Dengan Menggunakan Aplikasi Computer Based Testing (CBT)," Jurnal TEKNOIF, 2015.

[9] Ajat Rukajat, Teknik Evaluasi Pembelajaran, 1st ed. Jogjakarta: Deepublish, 2018.

[10] Samsul Hadi, Pengembangan Computerized Adaptive Test Berbasis Web, $1 \mathrm{st}$ ed. Sleman, Yogyakarta: Aswaja Pressindo, 2013.

[11] Sudaryono, Teori Respon Butir, 1st ed. Yogyakarta: Graha Ilmu, 2013.

[12] Anisa, "Perbandingan Penskoran Dikotomi dan Politomi dalam Teori Respon Butir untuk Pengembangan Bank Soal Matakuliah Matematika Dasar," Jurnal Matematika, Statistika, \& Komputasi, pp. 95-113, 2013.

[13] F. A. Nurcahyo, "Aplikasi IRT dalam Analisis Aitem Tes Kognitif," Buletin Psikologi, pp. 64-75, 2017.

[14] L. V. Aprillian and M. H. K. Saputra, Belajar Cepat Metode SAW, L. V. Aprillian, Ed.: Kreatif Industri Nusantara, 2020. 